\title{
Cooperative work behavior of high strength concrete-filled square high strength tubular stub columns with inner I-shaped CFRP under axial compression
}

\author{
G. Li*, Y. Yang, Z. Yang and Z. Zhan \\ School Of Civil Engineering, Shenyang Jianzhu University, China \\ *corresponding author, e-mail address: liguochang0604@sina.com
}

\begin{abstract}
The finite element software ABAQUS was used to analyze 22 high strength concrete-filled square high strength tubular short columns with inner I-shaped CFRP, all analysis results based on the finite element analysis data, six characteristic points were defined in the loadlongitudinal strain curve of composite columns. The shared load of core concrete, square steel tube and inner I-shaped CFRP at different height sections of typical specimen corresponding to each characteristic point were analyzed and the cooperative work behavior of inner I-shaped CFRP, square steel tube and core concrete was analyzed. The results show that the existence of the inner I-shaped CFRP can effectively improve the ultimate bearing capacity composite columns, the middle region I-shaped CFRP sharing more longitudinal load than the end region CFRP and the shared load of concrete at the end region section is bigger than that of middle region section, before the CFRP brittle failure. The longitudinal load of square steel tube does not change with the change of the crosssection height.
\end{abstract}

Keywords: Inner I-shaped CFRP; high strength square steel tube; high strength concrete; cooperative work behaviour; finite element analysis.

\section{Introduction}

Concrete-filled steel tube is divided into concrete filled circular steel tube, concrete filled elliptical steel tube and hollow concrete filled steel tube etc. For decades, a large number of theoretical and experimental studies have been carried out by academic researchers around the world on concrete-filled steel tube with different section forms. Li et al. [1] studied the behaviour of grout-filled double skin steel tubes under compression and bending by experimental research, the effect of different hollow ratio on its performance was compared. Zha et al. [2] proposed forward the bearing capacity formula of axial compression short column of ordinary concrete-filled steel tube, hollow concrete-filled steel tube, concrete filled circular steel tube and polygonal steel tube based on the unified theory of concrete-filled steel tube. Compare with the constrained stress between steel and concrete of concrete-filled square steel tube of concretefilled circular steel tube, there are less constrained stress between steel and concrete of concrete-filled square steel tube, but there is still strongly constrained stress between core concrete and square steel tube. At the same, concrete-filled square steel tube is widely used and studied, because of its convenient connection node and construction convenience [3]. Lee et al. [4] studied thin-walled rectangular concrete-filled tubular (RCFT) columns by experimental research. The parameter of width and thickness ratio, the yield strength of steel and the stiffener of RCFT were compared.

Zhao et al. [5] studied the mechanical properties of steel tube short columns filled with steel-reinforced concrete, which combined the concrete-filled steel tube and section reinforced concrete. Since then, the section steel reinforced concrete filled steel tube members have been further developed. The shapes of inner section steel members are divided into I-shaped or crossshaped ones. Section steel with different shape and many kinds of concrete-filled steel tube make up many kinds of section steel reinforce concrete-filled steel tube. In recent years, the development of section steel reinforce concretefilled steel tube is very rapid with its widely 
studied and applied. Steel tube, concrete and section steel work together in combined cross section of steel reinforced concrete filled steel tube. Because of the advantages of each part of the combined cross section, the cross-section area of the composite column has been reduced, besides, the strength and deformability of the core concrete and its seismic performance were improved. On the other hand, the inner section steel improves the fire resistance of ordinary CFST, meanwhile, it increases its bearing capacity, delays the development of concrete cracks and improves the ductility of concrete.

Due to their low self-weight, high durability, and reduced maintenance requirements, fiber reinforced polymer (FRP) pultruded profiles are becoming a competitive option as a kind of structural material [6]. A large number of experiments and theoretical studies have been carried out by many scholars all over the world on FRP materials. Pecce et al [7] studied the mechanical properties, buckling and failure modes of FRP profiles. With the application of FRP in structure, many scholars combined FRP with CFST and put forward a variety of composite components. Gu et al [8] have studied the CFRP-concrete-filled tubular stub columns under axial compression, at the same time, the working mechanism of the axial compression short column of the high performance concrete filled steel tube was analyzed. Sundarraja. M C et al [9-10] studied the compression performance of the CFRP reinforced concrete filled steel tube columns by theoretical and experimental research. At the same time, the combination of concrete-filled steel tube members with inner CFRP is also developing Li et al. [11-12] studied concrete-filled square steel tube columns with inner CFRP profiles under axial compression by finite element analysis and experimental study.

Compared with ordinary strength steel, high strength steel can reduce the section size of components, reduce welding material, coating dosage and construction workload. Highstrength concrete has the advantages of high strength, high rigidity and good durability. The application of high-strength materials not only effectively reduce the structural weight, but meet the requirements of the continuous development of the structure to a larger span and a higher height. [13-14].

Ordinary concrete-filled steel tubular members have been widely studied and applied for their excellent performance. However, the effect of high strength materials and CFRP on the behavior of concrete filled steel tube is remain to be further discussed. In this paper, the finite element analysis model of high-strength concrete-filled steel tubular high-strength concrete short columns with I-shaped CFRP is applied to study the cooperative work behavior of each part. The research of it lays the foundation for further research on the working mechanism of such components. By studying the mechanism of the cooperative work behavior of each component of the section, we can further study how to make full use of the material composition and optimize the cross section to find a more reasonable cross section form.

\section{Finite element model}

\subsection{Constitutive model of high-strength concrete}

In this paper, the plastic damage constitutive model of concrete is adopted. The core concrete of CFST is in the triaxial stress state. Therefore, constrain concrete compression constitutive model improved by Liu [15] is used in this paper adopted to simulate the compression behavior of core concrete. The stress-strain curve of high strength concrete is shown in Fig. 1. The constrain concrete compression constitutive model is calculated by the press formula:

$$
y= \begin{cases}2 x-x^{2} & x \leq 1 \\ \frac{x}{\beta_{0}(x-1)^{\eta}+x} & x>1\end{cases}
$$

where:

$$
\begin{gathered}
x=\frac{\varepsilon}{\varepsilon_{0}} \\
y=\frac{\sigma}{\sigma_{0}}
\end{gathered}
$$

$\sigma_{0}=f_{c}$ ' where $f_{c}$ ' is the cylinder strength of concrete, and it is calculated as $f_{c}{ }^{\prime}=f_{c u}-8$ [16].

$$
\begin{aligned}
& \varepsilon_{0}=\varepsilon_{\mathrm{e}}+800 \cdot \zeta_{s}^{0.2} \cdot 10^{-6} \\
& \eta=1.6+\frac{1.5}{x} \\
& \beta_{0}=\frac{\left(f_{c}^{\prime}\right)^{0.1}}{1.2 \cdot \sqrt{1+\zeta_{s}}}
\end{aligned}
$$




$$
\varepsilon_{\mathrm{e}}=\left(1300+12.5 \cdot f_{c}^{\prime}\right) \cdot 10^{-6}
$$

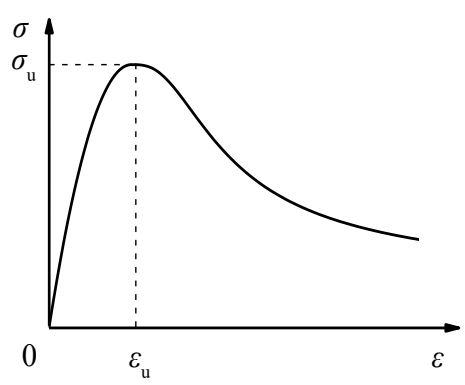

Fig. 1. Stress-strain curve for concrete.

The energy failure criterion is used to define the tensile softening performance of concrete because of its better computational convergence. The constitutive relation of stress-fracture energy is calculated by [16].

\subsection{Constitutive model of high-strength steel}

The steel tube is made of high strength steel. The two-fold line constitutive model of steel proposed by professor Han [3] is used in the material constitutive model. Fig. 2 is the stressstrain relationship curve of high-strength steel. Calculate the constitutive relation of steel as follow:

$$
\sigma_{s}= \begin{cases}E_{s} \cdot \varepsilon_{s} & \varepsilon_{s} \leq \varepsilon_{y} \\ \sigma_{y}+\left(\varepsilon_{s}-\varepsilon_{y}\right) \cdot E_{t} & \varepsilon_{y} \leq \varepsilon_{s} \leq \varepsilon_{u}\end{cases}
$$

where $\sigma_{s}$ represents the stress and $\varepsilon_{y}$ is the yield strain. $E_{s}$ is the elastic modulus of the elastic section and $E_{t}$ is the elastic plastic modulus of the elastic plastic section which takes $0.01 \cdot E_{s}$.

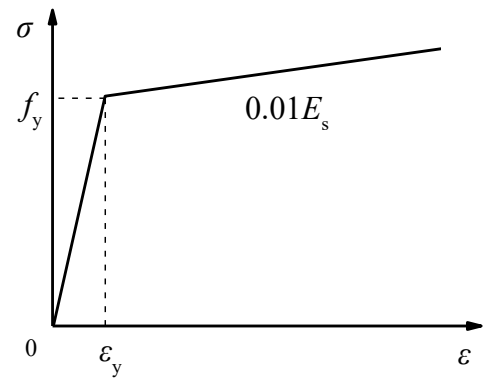

Fig. 2. Stress-strain curve of steel.

\subsection{Constitutive model of CFRP}

Longitudinal carbon fiber is used in the middle of the I-shaped CFRP profile. External carbon fiber cloth is wrapped round it. It can be regarded as an anisotropic material made up of three layers of different fiber directions.
The CFRP finite element model adopts the Tsai-Wu failure criterion, and the USDFLD subprogram based on the ABAQUS finite element analysis software is used to judge the failure process of the profile. The criteria for judgment are as follows:

$$
F_{11} \sigma_{1}^{2}+F_{22} \sigma_{2}^{2}+F_{66} \sigma_{6}^{2}+F_{1} \sigma_{1}+F_{2} \sigma_{2}+2 F_{12} \sigma_{1} \sigma_{2} \geq 1(6)
$$

where:

$$
F_{11}=\frac{1}{X_{t}}-\frac{1}{X_{c}}
$$

$$
\begin{aligned}
& F_{22}=\frac{1}{Y_{t}}-\frac{1}{Y_{c}} \\
& F_{12}=-\frac{1}{2}-\frac{1}{\sqrt{X_{t} \cdot X_{c} \cdot Y_{t} \cdot Y_{c}}} \\
& F_{66}=\frac{1}{S^{2}}
\end{aligned}
$$

\subsection{The establishment of the finite element model}

The finite element model of components are composed of four parts: plate, square steel tube, I-shaped CFRP and core concrete. The Continue Shell unit is used for the finite element model of I-shaped CFRP, and the Solid unit are used for other components. The components are shown in Fig. 3.

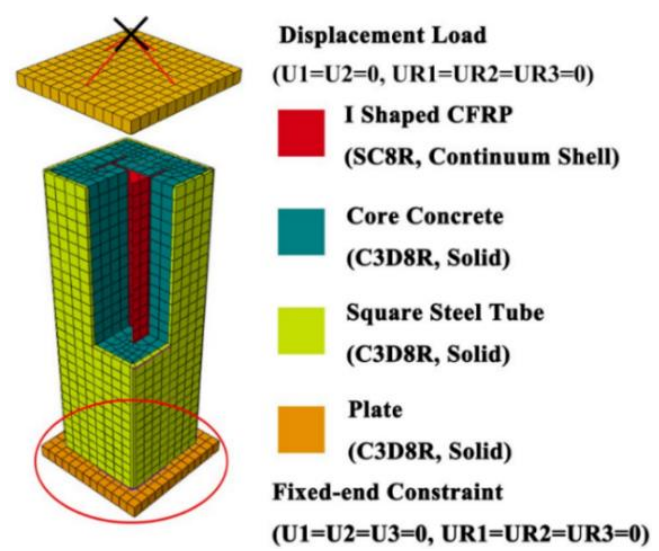

Fig. 3. Finite element model.

In Fig. 3, the I-shaped CFRP is Hard Contact with the plate, and Tie constraint is used to restrict the core concrete. The Hard Contact is used between core concrete and the plate are contacted by normal way, and the Hard Contact 
and the Frictional Contact are used between the core steel and the square steel tube. The square steel tube and the plate are Tie restrained. The boundary conditions of the component are as follow: The lower end plate boundary condition $(\mathrm{U} 1=\mathrm{U} 2=0$, UR $1=\mathrm{UR} 2=\mathrm{UR} 3=0$ ). The loading mode is loaded with displacement, and the loading point is coupled with the upper end plate. The boundary condition of the loading point is $(\mathrm{U} 1=\mathrm{U} 2=0$, UR $1=\mathrm{UR} 2=\mathrm{UR} 3=0) \mathrm{U} 3$ as the axial displacement.

Section of composite component is shown in Fig. 4. The component parameters are shown in Table 1 .

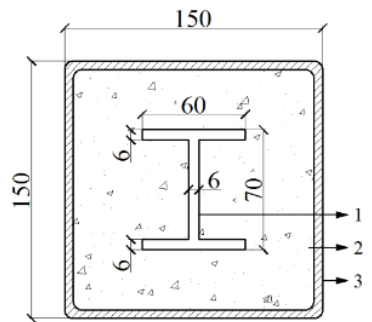

(1, I-shaped CFRP; 2, core concrete; 3, square steel tube)

Fig. 4. Section of composite component.

Table 1. Parameters of simulated models.

\begin{tabular}{|c|c|c|c|c|c|c|}
\hline $\begin{array}{l}\text { Num- } \\
\text { ber }\end{array}$ & $\begin{array}{l}\text { Size } \mathbf{B} \boldsymbol{x} \boldsymbol{h} \mathbf{x} \boldsymbol{L} \\
\quad(\mathrm{mm})\end{array}$ & $\boldsymbol{t}(\mathrm{mm})$ & $f_{\mathrm{y}}$ & $\begin{array}{c}f_{\mathrm{cu}} \\
(\mathrm{MPa})\end{array}$ & $f_{\mathrm{cf}}$ & $\begin{array}{c}\boldsymbol{P}_{\mathrm{u}} \\
(\mathrm{kN})\end{array}$ \\
\hline SC-1 & $150 \times 150 \times 450$ & 4 & 550 & 100 & 900 & 3575 \\
\hline SC-2 & $150 \times 150 \times 450$ & 4 & 690 & 100 & 900 & 3966 \\
\hline SC-3 & $150 \times 150 \times 450$ & 4 & 770 & 100 & 900 & 4182 \\
\hline SC-4 & $150 \times 150 \times 450$ & 4 & 890 & 100 & 900 & 4481 \\
\hline SC-5 & $150 \times 150 \times 450$ & 4 & 960 & 100 & 900 & 4656 \\
\hline SC-6 & $150 \times 150 \times 450$ & 4 & 550 & 80 & 900 & 3141 \\
\hline SC-7 & $150 \times 150 \times 450$ & 4 & 550 & 110 & 900 & 3792 \\
\hline SC-8 & $150 \times 150 \times 450$ & 5 & 550 & 100 & 900 & 3838 \\
\hline SC-9 & $150 \times 150 \times 450$ & 5 & 690 & 100 & 900 & 4338 \\
\hline SC-10 & $150 \times 150 \times 450$ & 5 & 770 & 100 & 900 & 4595 \\
\hline SC-11 & $150 \times 150 \times 450$ & 5 & 890 & 100 & 900 & 4995 \\
\hline SC-12 & $150 \times 150 \times 450$ & 5 & 960 & 100 & 900 & 5215 \\
\hline SC-13 & $150 \times 150 \times 450$ & 5 & 550 & 80 & 900 & 3422 \\
\hline SC-14 & $150 \times 150 \times 450$ & 5 & 550 & 110 & 900 & 4046 \\
\hline SC-15 & $150 \times 150 \times 450$ & 6 & 550 & 100 & 900 & 4000 \\
\hline SC-16 & $150 \times 150 \times 450$ & 6 & 690 & 100 & 900 & 4737 \\
\hline SC-17 & $150 \times 150 \times 450$ & 6 & 770 & 100 & 900 & 5049 \\
\hline
\end{tabular}

\begin{tabular}{lllllll}
\hline SC-18 & $150 \times 150 \times 450$ & 6 & 890 & 100 & 900 & 5483 \\
SC-19 & $150 \times 150 \times 450$ & 6 & 960 & 100 & 900 & 5736 \\
SC-20 & $150 \times 150 \times 450$ & 6 & 550 & 80 & 900 & 3614 \\
SC-21 & $150 \times 150 \times 450$ & 6 & 550 & 110 & 900 & 4194 \\
SC-22 & $150 \times 150 \times 450$ & 5 & 550 & 100 & - & 3454 \\
\hline
\end{tabular}

Notes: $t$ is the thickness of the steel tube, $f_{y}$ is the yield strength of the steel tube, $f_{c u}$ is the cube compressive strength of concrete, $f_{c f}$ is CFRP compressive strength, $P_{u}$ is the ultimate bearing capacity of the component, SC-22 is the contrast component without inner I-shaped CFRP profile.

\section{Force full-range analysis of component}

\subsection{Characteristic point analysis}

The stress-strain curve of typical component SC-8 as shown in the Fig. 5. Parameters of component SC-8: $B=150 \mathrm{~mm}, t=5 \mathrm{~mm}, L=450$ $\mathrm{mm}$, yield strength of steel tube $f_{y}=550 \mathrm{MPa}$, compressive strength of concrete cubes $f_{c u}=100$ $\mathrm{MPa}$, configuration rate of inner I-shaped CFRP is $4.75 \%$, CFRP compressive strength $f_{c F}=900$ $\mathrm{MPa}$. Six characteristic points are defined on the curve.

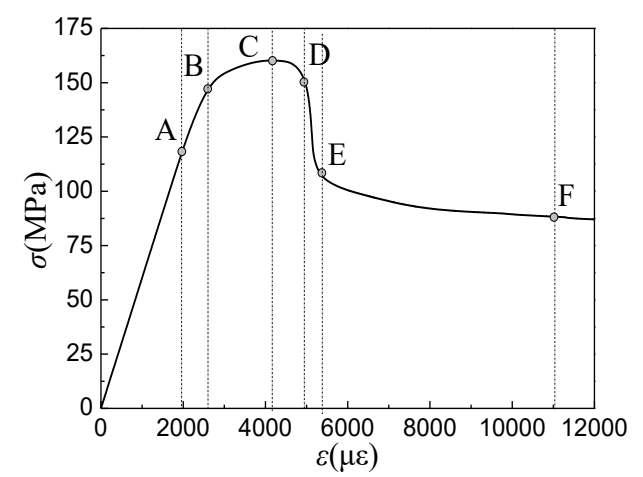

Fig. 5. Stress-strain curve of typical component SC8.

\subsection{Analysis of load distribution of each height section}

Fig. 7 is the curve of load shared by each member at every height in each characteristic point of the component SC-8. Fig. 7 (a), (b), (c), (d), (E) and (f) are the curve of load shared by each member at every height in characteristic points $\mathrm{A}, \mathrm{B}, \mathrm{C}, \mathrm{D}, \mathrm{E}$ and $\mathrm{F}$. The different height sections of the component are shown in Fig. 6.

Fig. 7(a) is the curve of load shared by each member of the component at every height in characteristic point A. At characteristic point A, the component is in the elastic state, and the distribution load of each group is uniform along 
the height. At this time, the concrete shares about $55.5 \%$ loads, the shared load of steel tube accounts for about $36.5 \%$ and the I-shaped CFRP shares about $8 \%$ load.

\section{Height of the section :}
(1) $\mathrm{H}=0 \mathrm{~mm}$
(6) $\mathrm{H}=125 \mathrm{~mm}$
(2) $\mathrm{H}=25 \mathrm{~mm}$
(7) $\mathrm{H}=150 \mathrm{~mm}$
(3) $\mathrm{H}=50 \mathrm{~mm}$
(8) $\mathrm{H}=175 \mathrm{~mm}$
(4) $\mathrm{H}=75 \mathrm{~mm}$
(9) $\mathrm{H}=200 \mathrm{~mm}$
(5) $\mathrm{H}=100 \mathrm{~mm}$
(10) $\mathrm{H}=\mathbf{2 2 5} \mathrm{mm}$

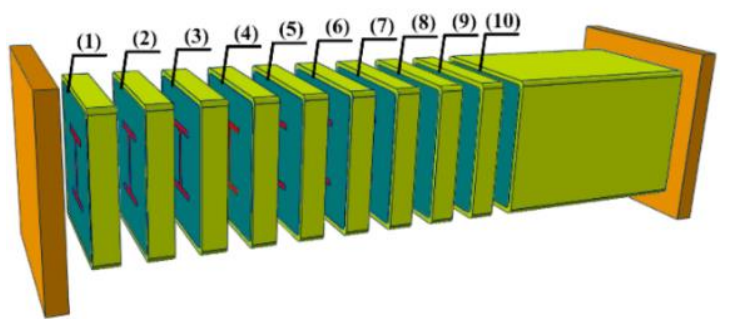

Fig. 6. Different heights of specimen section.

Figure 7 (b) is the curve of load shared by each member of the component at every height in characteristic point B. Under this characteristic point, full section of steel reaches the yield stage, and the concrete has entered the elastic-plastic stage. Under this characteristic point, it can be seen that the load of each high steel section is largely the same. It can be seen in figure that, the trend of concrete shared load at end region increases and the shared load of the end region section of concrete is slightly higher than that of the middle region section. Moreover, the CFRP shared load of the end section is slightly lower than the shared load of middle section; change range is less than $1 \%$. Compared with the previous characteristic points, the sharing load of the steel tube and the I-shaped CFRP increased by about $28.5 \%$, while the core concrete shared load increased by about $17 \%$. During the period of characteristic point A to characteristic point $\mathrm{B}$, the concrete entered the elastic-plastic state; meanwhile, the steel tube and I-shaped CFRP are still in elastic state.

Fig. 7(c) is the curve of load shared by each member of the component at every height in characteristic point $\mathrm{C}$. When the component reaches the characteristic point $\mathrm{C}$, the component reaches the ultimate loads. The shared load of steel tube is basically the same in the whole cross section, the load sharing rate is about $41 \%$ (load is about $1570 \mathrm{kN}$ ). At this time, the shared load of concrete has reached the maximum of the whole process. At the same time, the sharing load of the steel tube has no obvious change compared with the previous characteristic point and the I-shaped CFRP still bear the load. As is shown from the section height analysis, the loadsharing load of steel tube varies little with the height of the section, besides, the shared load of core concrete and I-shaped CFRP share the load changes larger with height. The core concrete divided about $52 \%$ longitudinal load (load about $2000 \mathrm{kN}$ ) from the $0 \mathrm{~mm}$ height section to the 25 $\mathrm{mm}$ height section, the shared load of core concrete decreased gradually, from the $25 \mathrm{~mm}$ height section to the $150 \mathrm{~mm}$ height section, while the height from $150 \mathrm{~mm}$ to $225 \mathrm{~mm}$, the shared load of concrete is distributed uniformly along the height, which is about $49.18 \%$ of the cross-section load (load is about $1786 \mathrm{kN}$ ). The trend of shared load of CFRP is opposite to the trend of concrete load sharing. From the $0 \mathrm{~mm}$ height section to the $25 \mathrm{~mm}$ height section, the CFRP shared load accounts for about $8.4 \%$ of the cross-section load (the load is about $327 \mathrm{kN}$ ), besides, from the $150 \mathrm{~mm}$ height section to the $225 \mathrm{~mm}$ height section, the CFRP shared load accounts for about $13 \%$ of the cross-section load (the load is about $505 \mathrm{kN}$ ). As is shown in the Fig. 7(c), compared with the characteristic point $\mathrm{B}$, the load increment of core concrete in the middle region is more obvious, while the load increase along the height of the I-shaped CFRP is even more obvious than the core concrete.

Fig. 7(d) is the curve of load shared by each member of the component at every height in characteristic point $\mathrm{D}$. When the characteristic point $\mathrm{D}$ is reached, the CFRP reaches the limit, the CFRP shared load varies greatly with the cross-section height. From $200 \mathrm{~mm}$ height section to $225 \mathrm{~mm}$ height section, the shared load of CFRP accounts for about $17.5 \%$ of the crosssection load (load is about $680 \mathrm{kN}$ ) and the shared load of CFRP reaches the maximum of the whole process. The height from $0 \mathrm{~mm}$ to 25 $\mathrm{mm}$, CFRP accounted for about $8.35 \%$ of the cross-section load (load is about $20 \mathrm{kN}$ ). From $25 \mathrm{~mm}$ to $200 \mathrm{~mm}$, the shared load of CFRP increases gradually in the cross section. The trend of CFRP shared load is opposite to the trend of shared load of concrete. At the characteristic point $\mathrm{D}$, the share load of the steel tube is about $40 \%$ (the load is about $1550 \mathrm{kN}$ ). The shared load of concrete is reduced and the concrete enters the decline stage after the characteristic point $\mathrm{C}$. The shared load of the end region of concrete accounts for about $50 \%$ of the cross-section load (load is about $1920 \mathrm{kN}$ ). The shared load of concrete in middle region is about $44.3 \%$ of the cross-section load (load is about 
$1620 \mathrm{kN})$. It can be seen from the Fig. 7(d) that, at the characteristic point $\mathrm{D}$, there is little change in shared load of concrete compared with the last characteristic point. The CFRP shared load increase in each height section, and concrete shared load reduce in each height section, the trend of the shared load along the height of concrete is the same as that of the characteristic point $\mathrm{C}$.

Fig. 7(e) is the curve of load shared by each member of the component at every height in characteristic point $\mathrm{E}$. When the member reaches characteristic point $\mathrm{E}$, the inner I-shaped CFRP brittle failure, the shared load at end region of concrete is also significantly reduced. It can be seen of the curve that the shared load of the steel tube is about $1470 \mathrm{kN}$, there is no obvious change of load in each height section. The shared load of concrete from the $0 \mathrm{~mm}$ height section to the $125 \mathrm{~mm}$ height section are significantly lower than that of characteristic point $\mathrm{D}$ (from the load in end region is $1920 \mathrm{kN}$, the load in $1 / 4$ cross section is $1820 \mathrm{kN}$ reduced to the load in end region is $1010 \mathrm{kN}$, and the load in $1 / 4$ cross section is $925 \mathrm{kN}$ ). The shared load of middle section concrete is increased, and the sharing load from the $200 \mathrm{~mm}$ height section to the 225 $\mathrm{mm}$ height section accounts for $36 \%$ of the section load (the load is $1225 \mathrm{kN}$ ). Although the middle section CFRP is brittle failure at the characteristic point $\mathrm{E}$, , CFRP still has a certain residual bearing capacity, still bear about $7 \%$ of the load, from the $0 \mathrm{~mm}$ height section to the 125 $\mathrm{mm}$ height section.

Fig. 7(f) is the curve of load shared by each member of the component at every height in characteristic point $\mathrm{F}$. When the component arriving at the characteristic point $\mathrm{F}$, there is little increment of the shared load of steel tube, besides, the trend of CFRP shared load and concrete shared load is basically the same as that of the characteristic point $E$. The share load of each part are further reduced. In the end section, the shared load of the I-shaped CFRP accounts for $4 \%$ of the cross-section load, and the shared load of the $1 / 4$ section accounts for $6.5 \%$ of the cross-section load, besides, the CFRP at middle section does not bear the load. The shared load of the concrete in end section accounts for $25 \%$ of the cross-section load, the $1 / 4$ section shared load accounts for $21.5 \%$ of the cross-section load, and the middle section share load accounts for $30.5 \%$ of the cross-section load. The load of steel tube varies slightly along each height section, the steel tube shared load accounts for about $70 \%$ of the cross-section load and the difference along the height is less than $1 \%$.

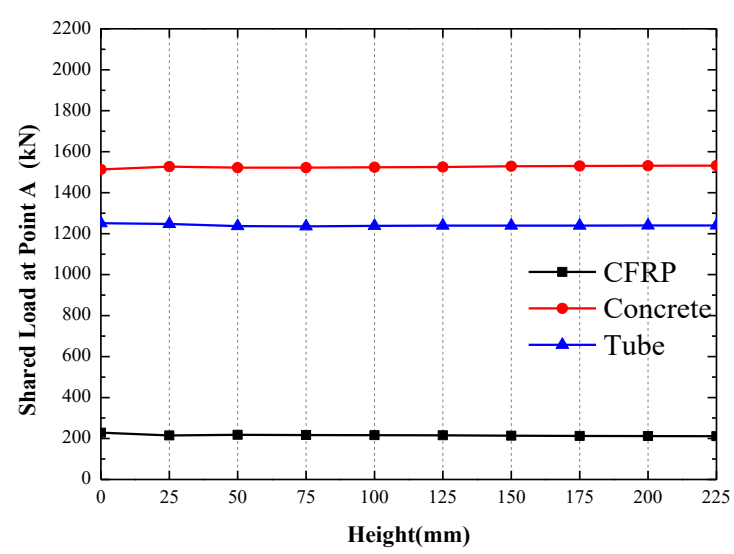

(a) Point A.

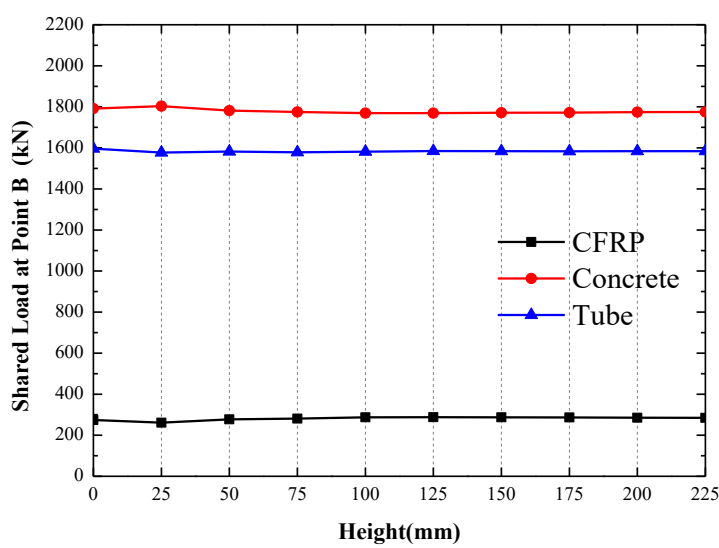

(b) Point B.

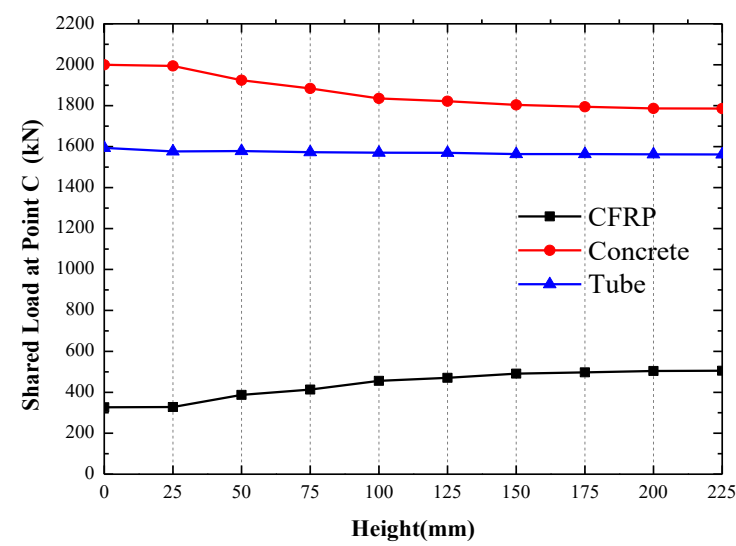

(c) Point C.

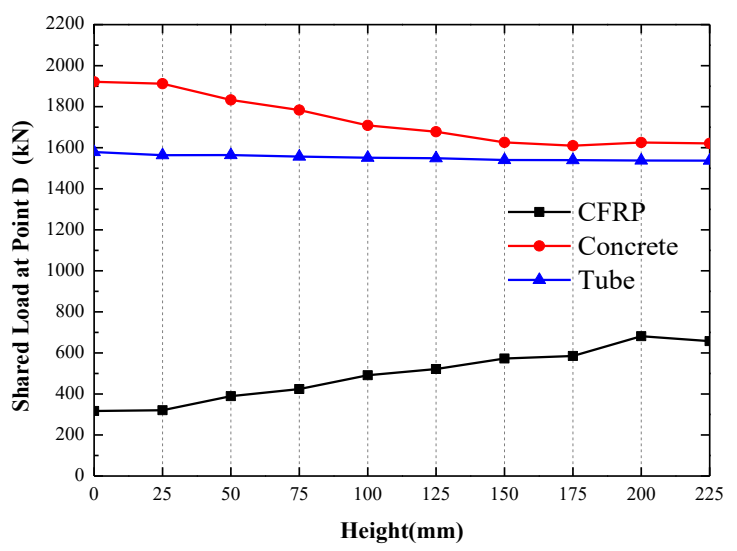

(d) Point D. 


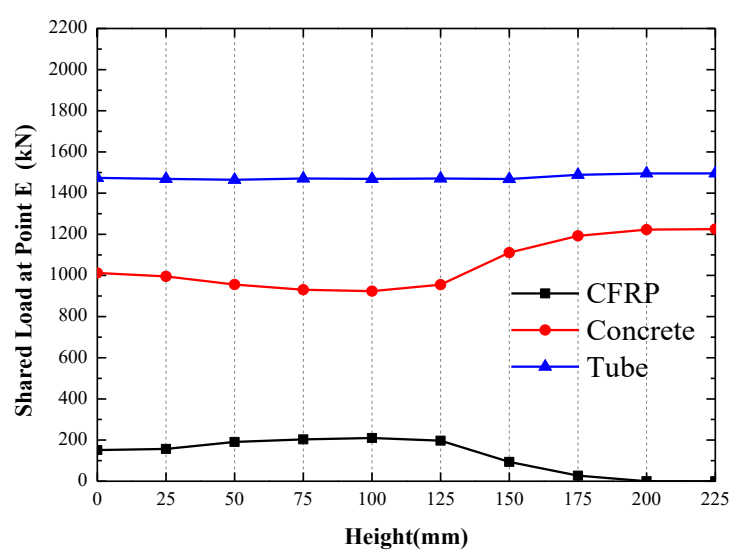

(e) Point E.

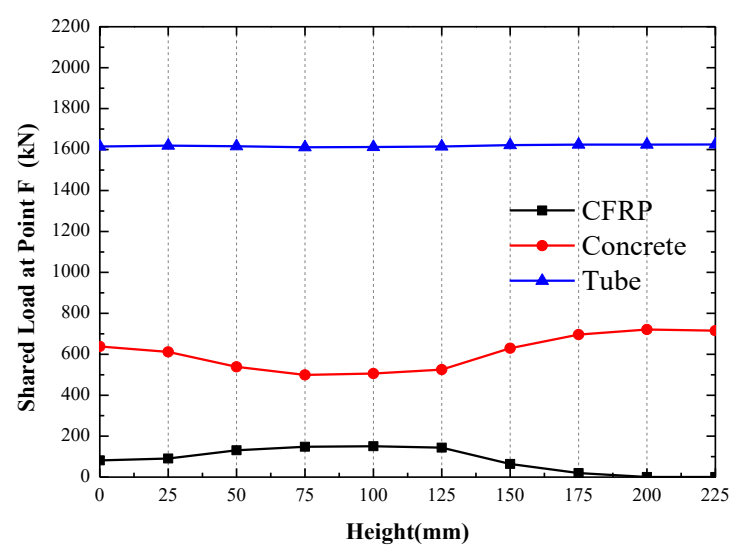

(f) Point F.

Fig. 7. The curve of load shared by each member at every height in each characteristic point of the component SC-8.

Fig. 8 is shared load of each part-height of section curve of component SC-8 at different characteristic points, Fig. 8 (a) (b) (c) are the corresponding curve of I-shaped CFRP, core concrete and square steel tube.

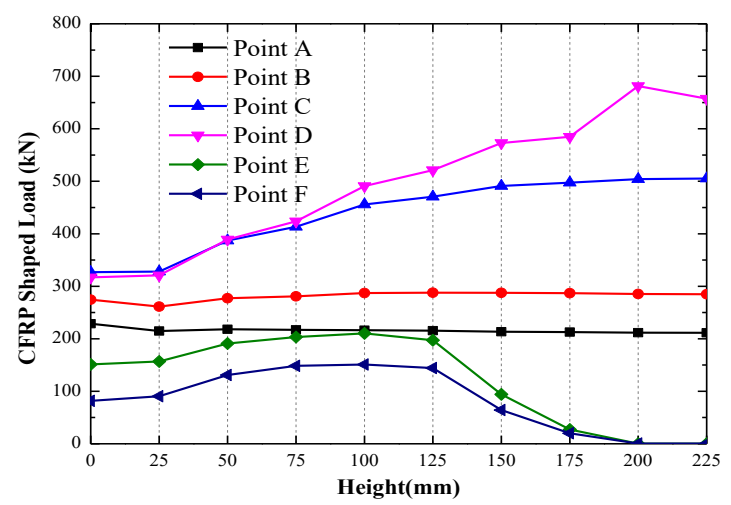

(a) I-shaped CFRP.

It can be seen in Fig. 8(a) that, before characteristic point $\mathrm{B}$, the shared load of CFRP is evenly distributed along the cross-section.

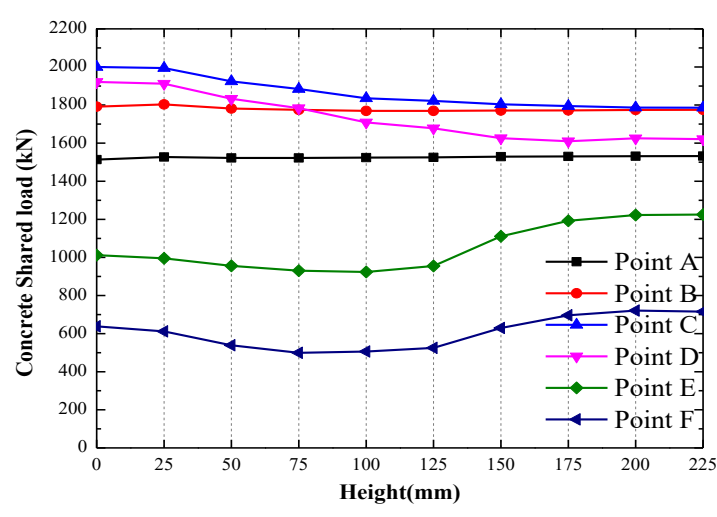

(b) Core concrete.

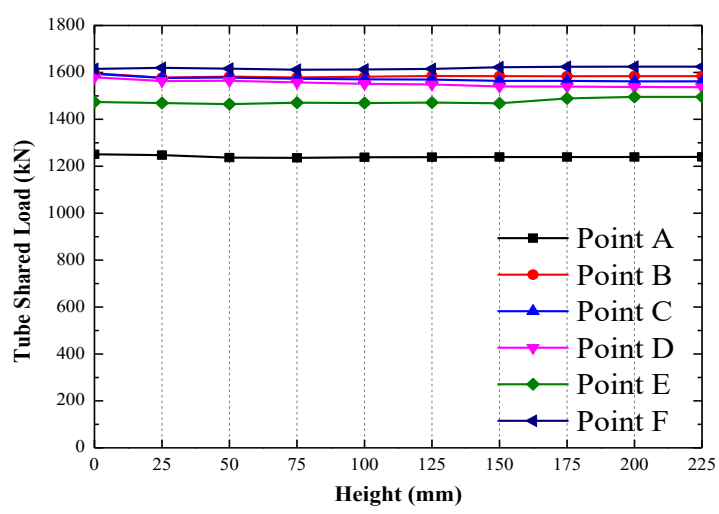

(c) Steel tube.

Fig. 8. Shared load of each part-height of section curve of component SC-8 at different characteristic points.

When the component reaches the characteristic point $\mathrm{C}$, component reach the ultimate bearing capacity, but the I-shaped CFRP has not reached the limit. It can be seen from the height distribution that, the shared load in middle region of the I-shaped CFRP is larger. When the characteristic point $\mathrm{D}$ is reached, the shared load of the I-shaped CFRP section increases further, while the load at the end section does not change significantly. At this time, the I-shaped CFRP reaches its ultimate bearing capacity. When the characteristic points $\mathrm{E}$ and $\mathrm{F}$ are reached, the I-shaped CFRP in middle region is destroyed, the CFRP at middle region cannot bear the load any more, and the end region of the I-shaped CFRP still has a certain residual bearing capacity.

It can be seen from Fig. 8(b) that concrete at characteristic point $\mathrm{A}$ and characteristic point $\mathrm{B}$ is uniform distributed along the height of section. When the characteristic point $\mathrm{C}$ arrives, the end region cross-section load of concrete increases, which reaches the maximum CFRP shared load of the whole process. At same time, 
the concrete shared load at central region does not increase. The trend of concrete shared load at the characteristic point $\mathrm{D}$ is just like the trend of characteristic point $C$, but the shared of concrete reduced in each height sections. When the characteristic point $\mathrm{E}$ and the characteristic point $\mathrm{F}$ arrive, the shared load of the concrete at middle section is about $1200 \mathrm{kN}$, which is higher than the end section concrete load (about $1000 \mathrm{kN})$.

It can be seen from Fig. 8(c) that there is no obvious change in the shared load of steel tube after the entry of the characteristic point $\mathrm{B}$, the load is shared evenly in each section.

\section{Conclusions}

In this paper, 22 high strength concrete-filled square high strength tubular short columns with inner I shaped CFRP are analyzed based on ABAQUS finite element analysis software. The situation of the shared load of each part in different height sections was analyzed with the change of the characteristic point. The results show that:

1) The shared load of the I-shaped CFRP in each height section of the component is the roughly same, in the elastic phase. After the characteristic point $B$ and before the CFRP brittle failure, shared load of CFRP in middle section is larger than that in end region. After reaching the feature point $\mathrm{E}$, the CFRP in middle region loss load sharing capacity, but there is still load capacity in end region.

2) The trend of concrete shared load in end section is larger, before the characteristic point E. After reaching characteristic point $\mathrm{E}$, the trend of concrete residual shared load in middle section is larger.

3) After entering the characteristic point B, the shared load of the steel tube does not change obviously with the change of the section height, and the shared load is evenly distributed along the height of the cross section in the whole process.

\section{References}

[1] Han LH, Li W, Bjorhovde R. Developments and advanced applications of concrete-filled steel tubular (CFST) structures: members. Journal of Constructional Steel Research 2014; 100: 211228.
[2] Wang YC. Tests on slender composite columns. Journal of Constructional Steel Research 1999; 49: 25-41.

[3] EN 1994-1-1. Eurocode 4. Design of composite steel and concrete structures. Part 1-1: General rules and rules for buildings. Brussels (Belgium): Comité Européen de Normalisation (CEN); 2004.

[4] ABAQUS. ABAQUS/standard version 6.14 user's manual. Dassault Systèmes, USA.

[5] Espinos A, Romero ML, Hospitaler A. Advanced model for predicting the fire response of concrete filled tubular columns. Journal of Constructional Steel Research 2010; 66: 1030-1046.

[6] Patel VI, Liang QQ, Hadi MNS. Nonlinear analysis of biaxially loaded rectangular concretefilled stainless steel tubular slender beamcolumns. Engineering Structures 2017; 140: 120 133.

[7] EN 1993-1-1. Eurocode 3. Design of steel structures. Part 1-1: General rules and rules for buildings. Brussels (Belgium): Comité Européen de Normalisation (CEN); 2005.

[8] EN 1992-1-1. Eurocode 2. Design of concrete structures. Part 1-1: General rules and rules for buildings. Brussels (Belgium): Comité Européen de Normalisation (CEN); 2004.

[9] Albero V, Espinos A, Romero ML, Hospitaler A, Bihina G, Renaud C. Proposal of a new method in EN1994-1-2 for the fire design of concretefilled steel tubular columns. Engineering Structures 2016; 128: 237-255.

[10] Sümer Y, Aktas M. Defining parameters for concrete damage plasticity model. Challenge Journal of Structural Mechanics 1 2015; $146-$ 155.

[11]FIB. Model Code 2010 (volume 1). Lausanne, Switzerland; 2010. 